\title{
Co-creating Patient-Oriented Discharge Instructions With Patients, Caregivers, and Healthcare Providers
}

\author{
Shoshana Hahn-Goldberg, PhD ${ }^{1 \star}$, Karen Okrainec, MD, MSc ${ }^{1,2}$, Tai Huynh, MBA ${ }^{1}$, Najla Zahr, BDes ${ }^{1}$, \\ Howard Abrams, MD, FRCPC ${ }^{1,2}$
}

${ }^{1}$ OpenLab, University Health Network, Toronto, Ontario, Canada; ${ }^{2}$ Department of Medicine, University Health Network, Toronto, Ontario, Canada.

For hospitalized patients, the transition from hospital to home is frequently accompanied by a significant amount of information to absorb. The objective of this work was to engage patients, caregivers, and healthcare providers in codeveloping patient-oriented discharge instructions, (ie, a brief transition plan with information that patients want). Overseen by a multidisciplinary advisory team, a participatory action approach using mixed methods was employed. Although formal inclusion and exclusion criteria were not used, deliberate efforts were made to engage groups with language barriers and limited health literacy. Symbols were designed and validated with the patient groups to represent each section of information to make the form more understandable for these patients. A prototype was codesigned using an iterative process. The form has been adapted for use in multiple health settings and is currently undergoing a multisite pilot to evaluate its effect on patient and provider experience. Journal of Hospital Medicine 2015;10:804-807. (C) 2015 Society of Hospital Medicine
The period following discharge from the hospital is a vulnerable time for patients that can result in adverse events including avoidable emergency room visits and rehospitalizations. ${ }^{1}$ Approximately $8.5 \%$ of all visits to the hospital result in readmissions within 30 days. $^{2}$ Poor communication of discharge information is even more pronounced for patients with language barriers or limited health literacy, particularly in ethnically diverse communities where up to $60 \%$ may speak languages other than English or French at home. ${ }^{3}$ Defined as "the degree to which individuals can obtain, process, and understand basic health information and services needed to make appropriate health decisions, ${ }^{4}$ an estimated $55 \%$ of Canadians between the ages of 16 and 65 years have limited health literacy, and only $12 \%$ of those above the age of 65 years have adequate health literacy skills. ${ }^{5}$

Previous authors have demonstrated the benefits of using multiple interventions, including nonverbal communication, when designing for individuals with limited literacy. ${ }^{6}$ Visual aids have been shown to be particularly useful to non-English speakers and patients with limited health literacy. ${ }^{7}$ In particular, research on medication tools for patients with limited health literacy has shown that illustrated schedules can be helpful. ${ }^{8}$

Typical discharge summaries are documents that are transmitted from the hospital to outpatient physicians

\footnotetext{
*Address for correspondence and reprint requests: Shoshana Hahn-Goldberg, OpenLab, Toronto General Hospital, 200 Elizabeth Street, Room G NU 403, Toronto, Ontario, Canada M5G 2C4; Telephone: 416-939-1507; E-mail: shoshana.hahn-goldberg@uhn.ca

Additional Supporting Information may be found in the online version of this article

Received: March 29, 2015; Revised: July 20, 2015; Accepted: July 24, 2015

2015 Society of Hospital Medicine DOI 10.1002/jhm.2444

Published online in Wiley Online Library (Wileyonlinelibrary.com).
}

to coordinate clinical care. The form codesigned by our team is intended to complement the summary and facilitate patient education and to provide instructions for patients to refer to after discharge.

\section{PURPOSE}

The objective of this work was to design instructions for patients going home from the hospital with relevant and actionable information, presented in an easily understandable and usable form.

\section{METHODS}

We used participatory action methodology, ${ }^{9}$ an approach to research that encourages researchers and those who will benefit from the research to work together across all phases of research, by engaging end-users of patient instructions from the beginning of the project. Mixed methods were used to understand needs, develop content and design, and iteratively evaluate and refine the instructions. An advisory team of patients, physicians, pharmacists, designers, researchers, and patient-education professionals gave input into study design and execution.

Although formal inclusion and exclusion criteria were not used, care was taken to engage patients with language barriers, limited health literacy, and mental health issues.

Key methods used are listed below. See Figure 1 for a timeline of the process used to develop the instructions.

\section{Understanding the Current Patient Experience of Discharge}

Key methods included: (1) Patient experience mapping ${ }^{10}$-a process of capturing and communicating complex patient interactions and their experience in the system by having interdisciplinary groups create a map of the patient experience and feelings through a mock discharge scenario). (2) A "cultural probe"11_patients selected as having minor language barriers or limited 


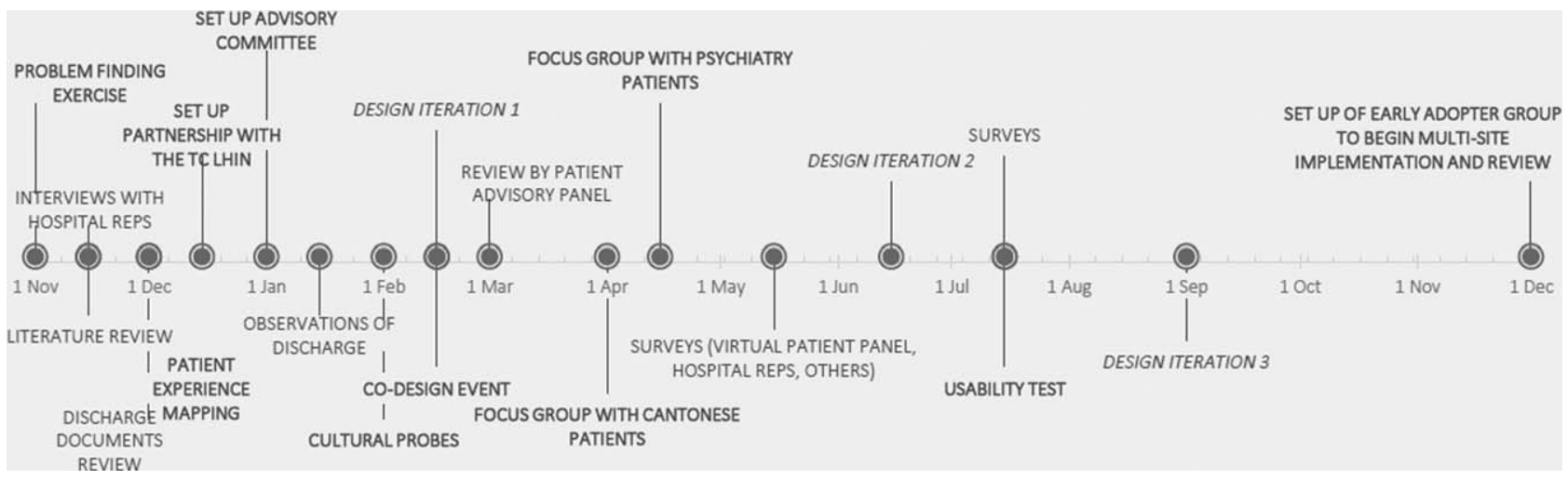

FIG. 1. Project timeline. Abbreviations: TC LHIN, Toronto Central Local Health Integration Network.

health literacy were given a journal and disposable camera to document their time at home after discharge. Patients were asked how confident they were in filling out medical forms by themselves as a way of screening for probable health literacy limitations. ${ }^{12}$

\section{Content and Design}

The instructions were developed using a "codesign" methodology, ${ }^{13}$ where researchers and the end-users of a product design the product together. In our case, teams of patients, healthcare providers, and designers worked together to create prototypes using hypothetical patient cases.

\section{Iteratively Evaluating and Refining the Design}

The prototype went through 3 design iterations (Figure 1). Feedback from patients, caregivers, and providers using focus groups, interviews, and surveys was used to refine the content and design and validate symbols for each section.

Key methods included: (1) Two focus groups with hard to reach patient groups that would not participate in interviews or surveys. One was with Cantonesespeaking patients, facilitated by an interpreter. Cantonese is a common language in Toronto, yet the language barrier typically precludes the patients from participating in research. The other group was with patients admitted to the psychiatry unit of the hospital, another group that typically is excluded from research studies. (2) Usability test of a paper-based version of the instructions across 3 large academic hospitals; physicians and residents in general internal medicine units filled out the instructions by hand for each patient discharged.

\section{RESULTS}

Forty-four patients, 12 caregivers, 30 healthcare personnel, 7 patient-education professionals, and 8 designers were involved in the design (see Figure 2 for an image of the template) based on best practices in information design, graphic design, and patient education.

\section{Understanding the Patient Experience of Discharge}

The analysis of the patient experience at discharge revealed the following themes:

(1) Difficulties in understanding and retaining verbal instructions in the immediate postdischarge period because of exhaustion. (2) Patient concerns at discharge including feeling unprepared to leave the hospital. (3) Family members and caregivers play a large role in a patient's life, which becomes more significant in the postdischarge phase. This was made clear through journal entries from patients using cultural probes.

\section{Content and Design}

Patients wanted to know information that was relevant and actionable. They consistently mentioned the following information as being most important: (1) medication instructions, (2) follow-up appointments with phone numbers, (3) normal expected symptoms, danger signs, and what to do, (4) lifestyle changes and when to resume activities, and (5) information and resources to have handy.

Advice from patient-education specialists on the team, as well as the feedback from patients and caregivers was that instructions should be written in language at a fifth- or sixth-grade level and be directed to the patient, use large fonts, include illustrations of medication schedules, and headings that are meaningful to the patient. In addition, patients wanted white space to take notes, an activity that has been shown to improve comprehension and recall. ${ }^{14}$

Patients felt having symbols for each section in the instructions helped make the form more readable by differentiating sections and providing a recognizable image for patients who could read English.

\section{Iteratively Evaluating and Refining the Design}

The results of the usability test data and surveys of the final version of the template showed that patients and providers felt that they would benefit from using the instructions. Of the patients and providers, $94.8 \%$ of patients and $75 \%$ of providers said that the instructions would be helpful to have when discharged from 
's Care Guide

I came to hospital on ___ _ _ and left on ___ _ _ _ _ _

my own notes

I came in because I have

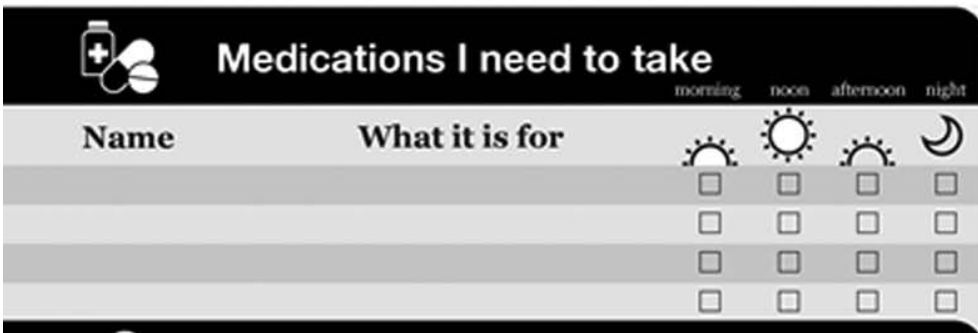

How I might feel and what to do

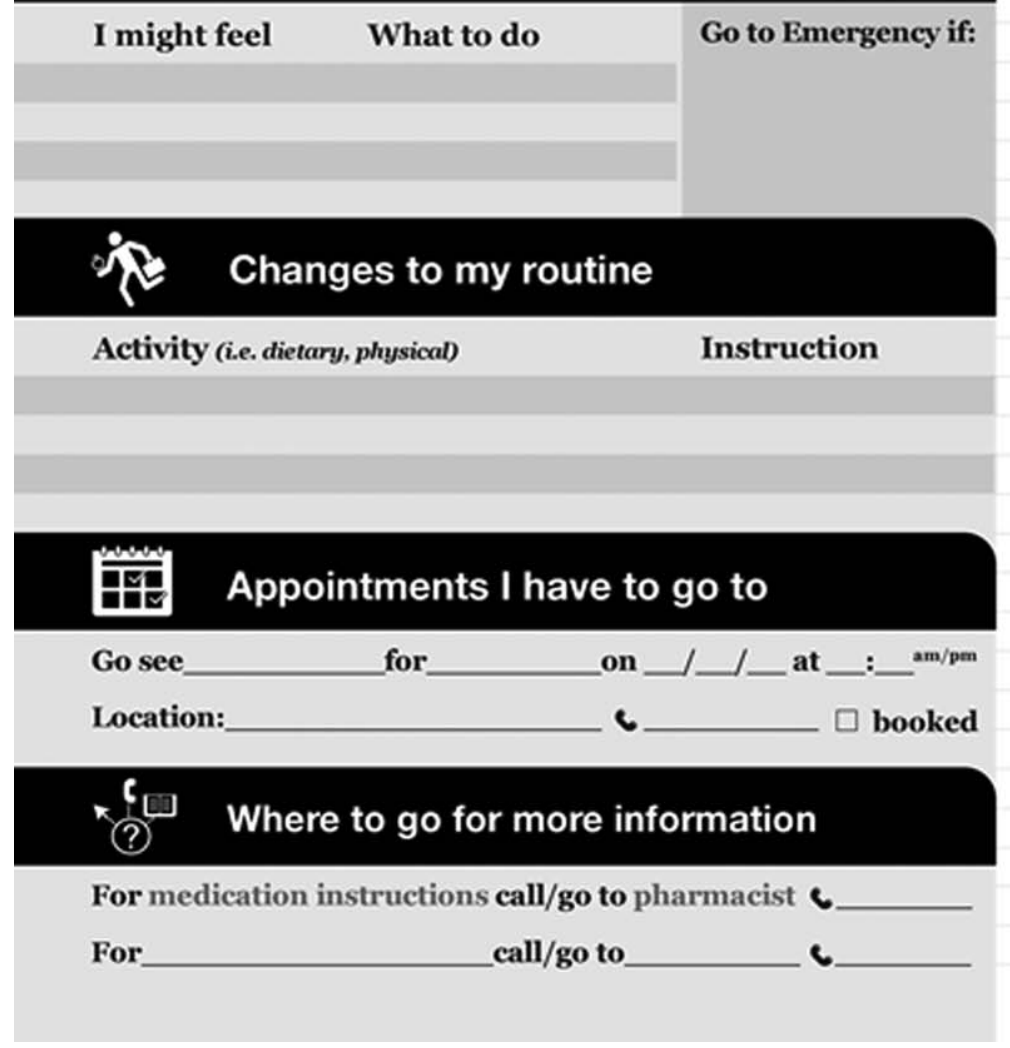

FIG. 2. Template.

the hospital. Physicians filling out the instructions by hand took an average of 9 minutes to fill out the form.

\section{DISCUSSION}

This initiative is an example of engaging patients and caregivers as active partners in the healthcare system. Patients and caregivers were engaged as codesigners of the form from the outset and continuously throughout.

The instructions can be given to patients and caregivers at discharge as both a teaching tool and a reference that can be reviewed when at home. Process considerations are very important. As family and caregivers play an instrumental role in postdischarge care, the instructions should be given whenever possible in the presence of family. The form is a simple addition to any discharge process. It can be filled out by a single provider, a multidisciplinary team, or even the patient while undergoing discharge teaching. The time and resources to fill out the instructions will vary depending on the discharge process in place. Good discharge practices, ${ }^{15}$ such as engaging the patient in the conversation and teach back, should be followed.

The form has been licensed as creative commons, so that any healthcare organization can use and adapt the materials to meet the needs of their patients.

The development of the form is only the first step in a larger project. Almost all of the study participants involved in the initiative were from the general internal medicine wards in downtown Toronto. We do not 
know yet if the results can be generalized to different patient and provider populations.

The instructions are currently being implemented in 8 hospitals throughout Toronto, spanning rehabilitation, acute care, surgery, and pediatrics. The form appears to have been appropriate and generalizable to all of these settings, but results from this multisite implementation on patient and provider experience or health outcomes are not available yet. Anticipated barriers include determining who has the responsibility for filling out the instructions and validating the accuracy of the medication list.

Discharge instructions serve many purposes. Though previous authors have developed checklists to ensure critical discharge information is included in discharge teaching, the creation of a patient-oriented form, codesigned with patients and caregivers to provide the information that patients explicitly want at discharge, has been lacking. Using participatory action research, mixed methods, and codesign methodology, and including hard-to-reach patient groups was helpful in creating a design that will provide patients with key information at discharge in an easy-to-understand format.

\section{Acknowledgements}

The authors acknowledge the financial support and guidance of the Toronto Central Local Health Integration Network. The project was advised by a number of individuals, namely: Cynthia Damba, Michelle Ransom, Paolo Korre, Irene Chong, Dawn Lim, Helen Kang, Derek Leong, Elizabeth Abraham, Elke Ruthig, Grace Eagan, Vivian Lo, Rachel Solomon, Kendra Delicaet, Sara Ahmadi, and Jess Leung.

Disclosures: The funding provided by the Toronto Central Local Health Integration Network that supported much of the work contained in this article also paid for a portion of the salaries of Shoshana Hahn-
Goldberg, Tai Huynh, and Najla Zahr. There are no other conflicts of interest to report.

\section{References}

1. Forster AJ, Murff HJ, Peterson JF, Gandhi TK, Bates DW. The incidence and severity of adverse events affecting patients after discharge from hospital. Ann Intern Med. 2003;138:161-167.

2. Jack BW, Chetty VK, Anthony D, et al. A reengineered hospital discharge program to decrease rehospitalization: a randomized trial. Ann Inter Med. 2009;150(3):178-187.

3. Statistics Canada. Visual census. 2011 census. Ottawa. Available at: http://www12.statcan.gc.ca/census-recensement/index-eng.cfm. Accessed September 19, 2014.

4. Committee on Health Literacy. Board on Neuroscience and Behavioral Health. Institute of Medicine. Health literacy: a prescription to end confusion. Washington, DC: National Academies Press; 2004. Available at: http://www.collaborationhealthcare.com/7-20-10IOMHealthLiteracyExecutiveSummary.pdf. Accessed September 19, 2014.

5. Rootman I, Gordon-El-Bihbety D. A vision for a health literate Canada: report of the Expert Panel on Health Literacy. 2008. Available at: http://www.cpha.ca/uploads/portals/h-1/report_e.pdf. Accessed September 19, 2014.

6. Sheridan S, Halpern D, Viera A, Berkman N, Donahue K, Crotty K. Interventions for individuals with low health literacy: a systematic review. J Health Commun. 2011;16:30-54.

7. Schillinger D, Machtinger EL, Wang F, Palacios J, Rodriguez M, Bindman A. Language, literacy, and communication regarding medication in an anticoagulation clinic: a comparison of verbal vs. visual assessment. J Health Commun. 2006;11(7):651-664.

8. Kriplani S, Robertson R, Love-Ghaffari M, et al. Development of an illustrated medication schedule as a low-literacy patient education tool. Patient Educ Couns. 2007;66(3):368-377.

9. Turnbull AP, Friesen BJ, Ramirez C. Participatory action research as a model for conducting family research. J Assoc Pers Sev Handicaps. 1998;23(3):178-188.

10. LaVela S, Gallan A. Evaluation and measurement of patient experience. Patient Exp J. 2014;1(1):28-36.

11. Gaver B, Dunne T, Pacenti E. Design: cultural probes. Interactions. $1999 ; 6(1): 21-29$.

12. Powers B, Trinh J, Bosworth H. Can this patient read and understand written health information? JAMA. 2010;304(1):76-84.

13. Sanders E, Stappers P. Co-creation and the new landscapes of design. Int J Cocreat Des Arts. 2008;4(1):5-18.

14. Mueller P, Oppenheimer D. The pen is mightier that the keyboard: advantages of longhand over laptop note taking. Psychol Sci. 2014; 25(6):1159-1168.

15. Soong, C, Daub, S, Lee, J, et al. Development of a checklist of safe discharge practices for hospital patients. J Hosp Med. 2013;8:444-449. 